\title{
Prevalence of bruxism among Mexican children with Down syndrome
}

\author{
Rubén López-Pérez', Patricia López-Morales² ${ }^{2}$ S. Aida Borges-Yáñez' , Gerardo \\ Maupomé ${ }^{3}$ and Gustavo Parés-Vidrio ${ }^{2}$
}

This study sought to determine the prevalence of bruxism in a Mexican community of children with Down syndrome, and to evaluate bruxism's relationship with age, sex, intellectual disability level, and type of chromosomal abnormality of trisomy 21. Using a cross-sectional design, 57 boys and girls ( 3 to 14 years old) were examined. Three approaches to establish presence or absence of bruxism were employed: parental questionnaire, clinical examination, and dental study casts. Data were analysed using bivariate analyses and conditional logistic regression. We found that the overall prevalence of bruxism was $42 \%$. No statistically significant associations between bruxism and age, sex, or intellectual disability level were found. There was, however, a significant association between bruxism and type of chromosomal abnormality, with mosaicism being more frequently associated with bruxism.

Bruxism has been defined as a mandibular parafunctional behaviour ${ }^{[1]}$ that is the forcible clenching or grinding of the teeth, or a combination of both. Clenching the teeth is the forceful closure of the opposing dentition in a static relationship of the mandible to the maxilla in either maximum intercuspation or eccentric positions. Grinding the teeth is the forceful closure of the opposing dentition in a dynamic maxillo-mandibular relationship as the mandibular arch moves through various excursive positions ${ }^{[2]}$. While bruxism may occur during the day or night, current polysomnographic and clinical studies have linked sleep-related bruxism to sleep disorders ${ }^{[3]}$. Sleep bruxism occurs primarily during the rapid eye movement phase of sleep ${ }^{[4]}$. The American Sleep Disorders Association defines bruxism as a periodic, stereotyped movement disorder of the masticatory system involving tooth grinding or clenching during sleep ${ }^{[5]}$.

The aetiology and characteristics of bruxism are not well understood ${ }^{[6]}$. The causes are probably multifactorial and overlapping ${ }^{[2]}$, and have been associated with several factors (BOX 1). Because of different research methods, operational definitions, clinical criteria, and study populations, the reported prevalence of bruxism varies in both adult and paediatric populations ${ }^{[2]}$. The prevalence in the general adult population has been reported between $3 \%$ and $90 \%{ }^{[1,3,6-11]}$.
Among children, prevalence ranges from $7 \%$ to $88 \%^{[1,3,6-14]}$. Previous studies ${ }^{[15,16]}$ have found that boys and girls without Down syndrome are equally likely to have bruxism, but one recent study ${ }^{[14]}$ posited that bruxism is more prevalent among boys.

Bruxism is considered a normal parafunctional pattern in the general paediatric population, presumably associated with changes in dentition. Children who brux begin at about four to eight years of age ${ }^{[6]}$. The incidence of bruxism is higher between 10 and 14 years of age, decreasing afterwards ${ }^{[2,17]}$. The most commonly observed consequence from bruxism is tooth wear, which can range from mild to severe wear facets - localised or generalised throughout the dentition. Other consequences affect supporting tissues ${ }^{[1]}$ : severe, long standing bruxism may result in muscle hyperthropy (usually in the masseter, but also in the temporal muscle ${ }^{[18]}$. Reported consequences of sleep bruxism include headaches, temporomandibular joint dysfunction, jaw pain, and pain when chewing ${ }^{[19,20]}$. Short-term acute therapy may involve physical therapy, nocturnal electromyographic biofeedback, and medication to relieve anxiety and improve sleeping. Longterm management generally includes some form of stress reduction, change in lifestyle, and an occlusal splint or night guard to protect the teeth and masticatory system ${ }^{[21]}$. 
Few studies have investigated the prevalence of bruxism in children with trisomy 21 . Researchers have reported prevalence figures between $18 \%$ and $70 \%{ }^{[13,22-25]}$. When compared with children without Down syndrome, investigators have found a higher prevalence of bruxism in boys and girls with trisomy $21^{[22,23,25]}$, and it has also been suggested that daytime bruxism is more common in children with Down syndrome due to spasticity ${ }^{[13]}$. However, no study has reported if age, sex, intellectual disability level, and type of chromosomal abnormality of the trisomy 21 influence the prevalence of bruxism in the population with Down syndrome. The objective of the present study was to characterise the factors associated with bruxism in a group of children with Down syndrome.

\section{Materials and Methods}

\section{Ethical implications}

The study's design and conduct complied with the regulations for the protection of human subjects stipulated by the organisations involved.

\section{Environment}

Using a cross-sectional study design, 86 children with Down syndrome studying at the John Langdon Down Foundation in 1998 were recruited. The Foundation is a not-for-profit organisation located in Mexico City that offers programmes delivering psychopaedagogical support and advice to persons with Down syndrome and their families. To participate in this study, volunteers provided verbal consent to an oral examination, including dental impressions. Their guardians/ parents provided written consent.

Of the 86 students, 29 were excluded from the study due to unsigned consent forms, or because they had ongoing maxillary orthopaedic or orthodontic treatment, were wearing oral prostheses, or because of assorted conditions such as epilepsy, autism, or cerebral palsy. The study group therefore included 57 children. No dental treatment was offered or carried out as part of the invitation to participate, but participants and guardians were given a summary of the oral health status findings for their treating dentist, if desired. No radiographs were taken.

\section{Variables collected}

We diagnosed bruxism using a questionnaire, intraoral examination, and dental study casts. A history of bruxism included grinding or clenching (day or night) as reported by parents through a questionnaire, while clinical indicators were the presence of dental wear facets in one or more primary and/or permanent teeth. The presence of wear facets detected during the intraoral

\section{Box 1 The many factors contributing to bruxism}

- Occlusal discrepancies ${ }^{[1,6,8,27,29]}$

- Mouth breathing and therefore a higher likelihood of dry mouth ${ }^{[8]}$

- Temporomandibular disorders ${ }^{[30,31]}$

Psychological factors:

- Emotional stress ${ }^{[2-4,6,7,19,41]}$

- Physical stress ${ }^{[2]}$

- Histamine release during stress ${ }^{[8]}$

- Anticipation of stress ${ }^{[2,9]}$

- Anger and frustration ${ }^{[7]}$

- Conscious and unconscious anxiety ${ }^{[8]}$

- Unconscious expression of oral gratification $^{[8]}$

- Inability to express anxiety, rage, hate, sadism, libidinous desires, and aggression $^{[8]}$

- Stringent educational attitude of parents $^{[8]}$

\section{Genetic factors:}

- Parents or blood relatives that were current bruxers or had a history of bruxing $^{[8]}$

\section{Neurological factors:}

- Rhythmic jaw movements altered in relation to chewing and swallowing ${ }^{[20}$

- Altered serotonin levels ${ }^{[4,42]}$

- An asymmetric nigrostriatal dopaminergic function ${ }^{[3]}$

- Stimulation of the limbic system ${ }^{[8]}$

- Autism ${ }^{[19]}$

- Cerebral palsy ${ }^{[8,19]}$

- Comatose patients ${ }^{[8]}$

- Disturbances of the central ${ }^{[1,2,6,8,9]}$, autonomic $^{[43]}$, and/or peripheral nervous systems ${ }^{[32]}$

\section{Local factors:}

\section{Factors associated with sleep:}

- Sleep disorders related to waking emotional states ${ }^{[2,9]}$

- Related to the stage of sleep ${ }^{[6]}$

- Nocturnal gastroesophageal reflux ${ }^{[33]}$

- Nocturnal swallowing-related laryngeal movement ${ }^{[34]}$

- Supine position when sleeping ${ }^{[34]}$

- Obstructive sleep apnea[sleep disordered breathing] ${ }^{[20,35-38]}$

\section{Systemic factors:}

- Potentially aggravated by the types of medications ${ }^{[2]}$

- Intestinal parasites ${ }^{[5,16,27]}$

- Subclinical nutritional deficiencies ${ }^{[5,16,27]} ; \mathrm{Mg}^{++}$deficiency ${ }^{[8]}$; vitamin deficiencies ${ }^{[8]}$

- Enzymatic imbalances indigestion causing chronic abdominal distress ${ }^{[8]}$

- Persistent recurrent urological dysfunction $^{[8]}$

- Endocrine disorders ${ }^{[5,16,27]}$

- Allergies ${ }^{[5,16,27]}$; allergic rhinitis, or asthma $^{[19]}$

- Forward head position due to cervical spine dysfunction ${ }^{[8]}$

\section{Social Factors:}

- Social deprivation ${ }^{[10]}$. Dissatisfaction with work ${ }^{[39]}$

Habits:

- Tobacco ${ }^{[40]}$

\section{Combined etiological factors:}

- Psychological and dental factors ${ }^{[8]}$. Somatogenic factors and psychogenic factors $^{[8]}$ consumption of alcohol and some

examination was confirmed in the dental study models.

The parental questionnaire also provided information regarding medical history and medication.

The intraoral examination was administered under artificial light with the patient lying down. The teeth were dried with cotton rolls and each tooth was examined using a No. 5 flat dental mirror. Standardisation was carried out by examining 20 patients, not included in the study population, on two occasions. The kappa value (intraexaminer variability) obtained by a calibrated paediatric dentist (PLM) was 0.98. 
Dental impressions were taken with alginate to make dental study casts (one upper and one lower plaster model). Again, the same clinical examiner performed standardisation training by evaluating 20 casts of patients not included in the study population, and re-examined them 15 days after the first examination. In this case, the kappa value (intraexaminer variability) was also 0.98 .

The control variables were sex (male or female), age (years and months), severity of intellectual disability measured by special educational needs (mild, moderate, or severe) (as per the John Langdon Down Foundation needs' assessment that structures the curriculum at the individual level), and the type of trisomy 21 chromosomal abnormality (regular, mosaicism, or translocation, as per the medical history chromosomal studies). This information was obtained from each child's medical history and the educational programme.

\section{Statistical analysis}

We used SPSS version 9.0 for data analysis. The chi-square test $\left(\chi^{2}\right)$ was employed to determine if there were statistically significant differences among subgroups according to age, sex, intellectual disability level, and type of chromosomal abnormality.

\begin{tabular}{|lrrrrrrrrr|}
\hline Age & \multicolumn{3}{c}{ Boys with bruxism } & \multicolumn{3}{c|}{ Girls with bruxism } & \multicolumn{3}{c|}{ Total with bruxism } \\
(years;months) & $\mathrm{n}$ & $\mathrm{f}$ & $(\%)$ & $\mathrm{n}$ & $\mathrm{f}$ & $(\%)$ & $\mathrm{n}$ & $\mathrm{f}$ & $\%$ \\
\hline $3 ; 00-5 ; 11$ & 4 & 0 & 0 & 3 & 2 & 67 & 7 & 2 & 29 \\
$6 ; 00-8 ; 11$ & 13 & 6 & 46 & 9 & 6 & 67 & 22 & 12 & 59 \\
$9 ; 00-11 ; 11$ & 11 & 5 & 46 & 7 & 4 & 57 & 18 & 9 & 50 \\
$12 ; 00-14 ; 11$ & 6 & 1 & 17 & 4 & 0 & 0 & 10 & 1 & 10 \\
Total & 34 & 12 & 35 & 23 & 12 & 52 & 57 & 24 & 42 \\
\hline
\end{tabular}

Table 1 Prevalence of bruxism by age and sex in a population with Down syndrome. $n=$ number of children examined. $f=$ frequency. Difference between age subgroups: $x^{2}=5.50, p=0.36$ Difference between sexes: $x^{2}=0.00, p=1.00$

\begin{tabular}{|lrrr|}
\hline Special & \multicolumn{3}{c|}{ n with bruxism } \\
education needs & $\mathrm{n}$ & $\mathrm{f}$ & $(\%)$ \\
\hline Mild & 23 & 9 & 39 \\
Moderate & 24 & 11 & 46 \\
Severe & 6 & 3 & 50 \\
Total & 53 & 23 & 43 \\
\hline
\end{tabular}

Table 2 | Prevalence of bruxism by intellectual disability level (special education needs) in a Mexican paediatric group with Down syndrome. $n=$ number of children examined. $f=$ frequency. . Difference between intellectual disability level subgroups: $x^{2}=4.52 ; p=0.10$

\begin{tabular}{|lrrr|}
\hline $\begin{array}{l}\text { Type of } \\
\text { chromosomal } \\
\text { abnormality }\end{array}$ & \multicolumn{4}{c|}{ n with bruxism } \\
\hline Regular & $\mathbf{f}$ & (\%) \\
Mosaicism & 11 & 8 & 73 \\
Translocation & 5 & 2 & 40 \\
Total & 52 & 22 & 42 \\
Table 3 | Prevalence of bruxism by type of \\
chromosomal abnormality in a Mexican \\
paediatric group with Down syndrome. \\
$\mathbf{n}=$ number of children examined. \\
f= frequency. Difference between type of \\
chromosomal abnormality subgroups: $x^{2}=$ \\
$6.91 ; p=0.032$
\end{tabular}

\section{Results}

\section{Basic results}

Age and sex distribution: there were 34 boys (60\%) and 23 girls (40\%). Age range was 3.0-14.1 years old (mean age 8.67 years \pm 2.96 ). Bruxism was diagnosed in 24 of the 57 children (42\%).

\section{Prevalence of bruxism by age and sex}

Bivariate analyses. As shown in TABLE 1, there was no significant difference in the prevalence of bruxism when children were arbitrarily divided into four age subgroups $\left(\chi^{2}=5.50, p=0.36\right)$. This habit was most common in the $6 ; 00$ to $8 ; 11$ year age group, with bruxism decreasing in frequency in the older group. There was no significant difference in the prevalence of bruxism when compared by sex, where 12 boys (35\%) and 12 girls (52\%) were bruxists $\left(\chi^{2}=0.00, p=1.00\right)$.

\section{Prevalence of bruxism by intellectual disability level}

Bivariate analyses. Intellectual disability was measured by special education needs. TABLE 2 shows that there was no significant difference among children with different levels of special education needs $\left(\chi^{2}=4.53, p=0.10\right)$.

\section{Prevalence of bruxism by type of trisomy 21 chromosomal abnormality}

Bivariate analyses. The type of trisomy 21 was known in 52 individuals. As shown in TABLE 3, children with mosaic trisomy had the highest bruxism prevalence $\left(\chi^{2}=6.91, p=0.03\right)$.

\section{Multivariate logistic regression model}

TABLE 4 presents results derived from a conditional logistic regression model (stepwise) incorporating the four independent variables. Children with Down syndrome with mosaicism had five times higher probability of having bruxism than other children with Down syndrome.

\begin{tabular}{|lrrrr|}
\hline Variables & $\boldsymbol{p}$ & Odds & \multicolumn{2}{c|}{$95 \%$ C.I. } \\
& & ratio & Lower & Upper \\
\hline SEX male & 0.08 & 0.31 & 0.084 & 1.13 \\
CA regular & 0.10 & - & - & - \\
CA mosaicism & 0.03 & 6.03 & 1.18 & 30.77 \\
CA translocation & 0.82 & 1.26 & 0.17 & 9.35 \\
Constant & 0.94 & 1.04 & - & - \\
\hline
\end{tabular}

Table 4 | Model of logistical regression controlling: sex, chromosomal abnormality (CA), special education needs, and age in a Mexican paediatric group with Down syndrome. Variables entered on step 1: sex, chromosomal abnormality, special education needs, and age. 


\section{Discussion}

The present study confirms the strength of the association between signs and history of tooth grinding in children with Down syndrome and some of the more salient features that characterise subgroups of children with this disability. We found a fairly high percentage of this behaviour ( $42 \%$ prevalence) in the community studied - with age modifying the experience. When contrasted with other reports in the literature, we found that the prevalence was much higher in other places - Gullikson ${ }^{[22]}$ reported a prevalence of $79 \%$ in 28 American children with Down syndrome between 3-10 years old; Alari ${ }^{[13]}, 70 \%$ in 21 Spanish children (age range, 6 to 7 years); Bell et al. ${ }^{[25]}, 67 \%$ in 49 Australian children; and Borea et al. ${ }^{[23]}, 45 \%$ in 37 Italian children (mean age, 12 years old). Only Hernández et al., ${ }^{[24]}$ reported lower figures - again in a Mexican population - $18 \%$ in 61 children (range 6 to 14 years). The different ages in the various study populations might account for the observed discrepancies.

The latter speculation gains strength when considering changes across age groups in the present study. As we were limited to a cross-sectional design, we cannot draw conclusions in terms of longitudinal trends. But we may contrast different age groups, and venture some explanations that may be relevant to developmental changes along the age continuum. When comparing the prevalence of bruxism by age subgroups, the children examined in this study exhibited similar patterns of bruxism to those found in the general paediatric population - the highest prevalence of this parafunction was found in the subgroup of children between 6;00 to $8 ; 11$ years. Prevalence decreased in the older age groups. In the general population, the frequency of grinding appears to increase up to age $7^{[8]}$, but other authors indicated that prevalence is at its highest between 10 to 14 years of age $\mathrm{e}^{[2]}$. Most investigators agree that bruxism increases during the mixed dentition stage $^{[8]}$, and decreases with age $e^{[2,8,17]}$, even though some reports disagreed with these interpretations, based on their findings of similar prevalence of bruxism in teenagers and adults ${ }^{[9]}$, and similar prevalence in children with and without mixed dentition $^{[26]}$.

Compounding the trends identified for age and sex also provided interesting contrasts. Our findings concurred with studies which found no significant prevalence differences between boys and girls (3 to 17 years of age ${ }^{[15,16]}$, but disagreed with the higher prevalence in boys reported by Shetty and Munshi ${ }^{[14]}$. Future research might address this seemingly conflicting pattern of findings by carefully controlling for tooth eruption/shedding variation across sexes, which may be the crux of these reported differences, or a contributing factor.

The only other study to address intellectual disability levels in relation to bruxism is the investigation reported by Borea et al., ${ }^{[23]}$. They examined patients with Down syndrome with intellectual disability from mild to severe and, just as we found, there appears to be no association between these two variables.

Some methodological limitations apply to the present study. Results cannot be extrapolated to the overall population with Down syndrome in Mexico, in particular because this is a highly detailed study in a small, well-defined population, but also because no reliable Down syndrome national figures are available. Furthermore, the student population at the John Langdon Down Foundation probably represents a population who have highly-structured, well-documented educational and medical programmes that meet their needs. Other children with Down syndrome may have less advantageous oral health or educational situations or diagnoses. More relevant to the design aspects of the present study is a methodological limitation that has plagued studies in the past - how to diagnose bruxism. The errors expected when using a questionnaire or an interview to collect information about bruxism tend to underestimate or overestimate the incidence. Although dental wear can be objectively measured, this might not indicate the current level of bruxism because individuals who bruxed in the past may present with dental facets, while subjects who recently began bruxing may not yet have signs of dental wear ${ }^{[27,28]}$. While the reliability tests in some studies have shown acceptable variability ${ }^{[27]}$, a minority of authors have indicated that the use of polysomnographic cut-off criteria to discriminate the presence or absence of sleep bruxism should be an integral part of the diagnostic procedure ${ }^{[3]}$. In the present study we met this challenge by diagnosing bruxism only when positive reports were gathered through the questionnaire, the intraoral examination, and the analysis of dental models. We suggest that this three-pronged approach constitutes as validated a criterion as may reasonably be attained.

In summary, the present study found that children with Down syndrome between 3;00 to $14 ; 11$ years old had a $42 \%$ prevalence of bruxism. The prevalence of bruxism was not different for boys or girls, was similar to that reported in the general paediatric population, and was more frequent in children $6 ; 00$ to $8 ; 11$ years old. Furthermore, intellectual disability levels had no apparent relationship to the experience of bruxism. There was a significant difference, however, across the different types of trisomy 21, with mosaicism being the type that had the higher prevalence. 
1. Attanasio R. Nocturnal bruxism and its clinical management, Dental Clinics of North America. 1991;35(1):245-252

2. Attanasio R. An overview of bruxism and its management, Dental Clinics of North America. 1997; 41(2):229-241.

3. Lobbezoo F, Lavigne GJ. Do bruxism and temporomandibular disorders have a causeand-effect relationship? Journal of Orofacial Pain. 1997;11(1):15-23.

4. Bell WE. Temporomandibular Disorders. Classification, Diagnosis, Management. Chicago: Year Book Medical Publishers, Inc. 3a. ed. 395;1990.

5. Sari S, Sonmez H. The relationship between occlusal factors and bruxism in permanent and mixed dentition in Turkish children. Journal of Clinical Pediatric Dentistry. 2001;25(3):191-194.

6. Negoro T, Briggs J, Plesh O, Nielsen I, McNeill C, Miller AJ. Bruxing patterns in children compared to intercuspal clenching and chewing as assessed with dental models, electromyography, and incisor jaw tracings preliminary study. Journal of Dentistry for Children. 1998;65(6):449-458.

7. Glaros AG. Incidence of diurnal and nocturnal bruxism. The Journal of Prosthetic Dentistry. 1981 45(5):545-549.

8. Cash RG. Bruxism in children: Review of the literature. Journal of Pedodontics. 1988;12:107-126.

9. Seligman DA, Pullinger AG, Solberg WK. The prevalence of dental attrition and its association with factors of age, sex, occlusion, and TMJ symptomatology. Journal of Dental Research. 1988;67(10):1323-1333.

10. Milosevic A, Young PJ, Lennon MA. The prevalence of tooth wear in 14-year-old school children in Liverpool. Community Dental Health. 1994;11(2):83-86

11. Tsolka P, Walter JD, Wilson RF, Preiskel HW. Occlusal variables, bruxism and temporomandibular disorders: a clinical and kinesiographic assessment. Journal of Oral Rehabilitation. 1995; 22:849-856.

12. Burakoff R. Epidemiology. In Kaplan AS and Assael LA. Temporomandibular Disorders. Diagnosis and Treatment. Philadelphia: W.B. Saunders Company; 1991. p.95-103

13. Alarí BME. 1994 [The infantile bruxism. En Contacto. 1994;XV: 3-4.] Spanish.

14. Shetty SR, Munshi AK. Oral habits in children - a prevalence study. Journal of Indian Society Pedodontics Preventive Dentistry. 1998;16(2):61-66.

15. Reding GR, Rubright WC, Zimmerman SO. Incidence of bruxism. Journal of Dental Research. 1966;45(4):1198-1204.

16. Kuch EV, Till MJ, Messer LB. Bruxing and nonbruxing children: A comparison of their personality traits. Pediatric Dentistry. 1979;1(3):182-187.
17. Kieser JA, Groenveld HT. Relationship between juvenile bruxing and craniomandibular dysfunction. Journal of Oral Rehabilitation. 1998; 25(9): 662-665.

18. Carlsson GE, Magnusson T. Management of temporomandibular disorders in the general practice. Chicago: Quintessence Publishing Co, Inc. 192; 1999.

19. Weideman CL, Bush AL, Yan-Go FL, Clark GT, Gornbein JA. The incidence of parasomnias in child bruxers versus nonbruxers. Pediatric Dentistry. 1996;18(7):456-460.

20. Lavigne GJ, Kato T, Kolta A, Sessle BJ. Neurobiological mechanisms involved in sleep bruxism. Critical Review of Oral Biological Medicine. 2003; 14(1):30-46.

21. Rugh JD, Harlan J. Nocturnal bruxism and temporomandibular disorders. Advances in Neurology. 1988;49:329-341.

22. Gullikson JS. Oral findings in children with Down's syndrome. Journal of Dentistry for Children. 1973;July-August:293-297.

23. Borea G, Magi M, Mingarelli R, Zamboni, C. The oral cavity in Down's syndrome. Journal of Pedodontics. 1990;14(3):139-140.

24. Hernández PJ, Tello HT, Ochoa RG. [Oral alterations in children with Down's syndrome from Yucatán state. Revista ADM. 1998; LV(2):91-96.] Spanish.

25. Bell EJ, Kaidonis J, Townsend GC. Tooth wear in children with Down's syndrome. Australia Dental Journal. 2002;47(1):30-35.

26. Cheng $\mathrm{HJ}$, Chen $\mathrm{YQ}, \mathrm{Yu} \mathrm{CH}$, Shen $\mathrm{YQ}$.[The influence of occlusion on the incidence of bruxism in 779 children in Shangai. Shangai Kou Quang Yi Xue. 2004;13(2):98-99.] Chinese.

27. Vanderas AP, Manetas KJ. Relationship between malocclusion and bruxism in children and adolescents: a review. Pediatric Dentistry. 1995;17(1): 7-12.

28. Baba K, Haketa T, Clark GT, Ohyama T. Does tooth wear status predict ongoing sleep bruxism in 30 year-old Japanese subjects? International Journal of Prosthodontics. 2004;17(1):39-44.

29. Jorgic-Srdjak K, Ivezic S, Cekic-Arambasin A, Bosnjak A. Bruxism and psychobiological model of personality. Collegium Antropologicum. 1998; 22 Suppl: 205-212.

30. Guler N, Yatmaz PI, Ataoglu H, Emlik D, Uckan S Temporomandibular internal derangement: correlation of MRI findings with clinical symptoms of pain and joint sounds in patients with bruxing behaviour. Dentomaxillofacial Radiology. 2003; 32(5):304-310.

31. Manfredini D, Cantini E, Romagnoli M, Bosco M. Prevalence of bruxism in patients with different research diagnostic criteria for temporoman- dibular disorders (RDC/TMD) diagnoses. Cranio. 2003;21(4):279-285.

32. Kato $\mathrm{T}$, Thie NM, Hoyah N, Miyawaki S, Lavigne GJ. Topical review; sleep bruxism and the role of peripheral sensory influences. Journal of Orofacial Pain. 2003;17(3):187.

33. Miyawaki $S$, Tanimoto $Y$, Araki K, Katayama A, Fujii A, Tacano-Yamamoto T. Association between nocturnal bruxism and gastroesophageal reflux. Sleep. 2003;26(7):888-892.

34. Miyawaki S, Lavigne GJ, Pierre M, Guitard F, Montplaisir JY, Kato T. Association between sleep bruxism, swallowing-related laryngeal movement, and sleep positions. Sleep. 2003;26(4):461465.

35. Okeson JP, Phillips BA, Berry DT, Cook YR, Cabelka JF. Nocturnal bruxing events in subjects with sleep-disordered breathing and control subjects. Journal of Craniomandibular Disorders. 1991;5(4):258-264.

36. Sjoholm TT, Lowe AA, Miyamoto K, Fleetham, JA, Ryan CF. Sleep bruxism in patients with sleepdisordered breathing. Archives of Oral Biology. 2000;45(10):889-896.

37. Oksenberg, A, Arons E. Sleep bruxism related to obstructive sleep apnea: the effect of continuous positive airway pressure. Sleep Medicine. 2002; 3(6):513-515.

38. Winocur E, Gavish A, Voikovitch M, Emodi-Perlman A, Eli I. Drugs and bruxism: a critical review. Journal of Orofacial Pain. 2003;17(2):99-111.

39. Ahlberg $\mathrm{K}$, Ahlberg J, Kononer M, Partinen $M$ Lindholm H, Savolainen A. Reported bruxism and stress experience in media personnel with or without irregular shift work. Acta Odontologica Scandinavica. 2003;61(5):315-318.

40. Ahlberg J, Savolainen A, Rantala M, Lindholm H, Kononen M. Reported bruxism and biopsychosocial symptoms: a longitudinal study. Community Dentistry and Oral Epidemiology. 2004;32(4):307311.

41. Vanderas AP, Menenakov M, Kovimtzis TH, Papagiannoulis L. Urinary catecholamine levels and bruxism in children. Journal of Oral Rehabilitation. 1999;26,103-110.

42. Bostwick JM, Jaffee MS. Buspirone as an antidote to SSRI-induced bruxism in 4 cases. Journal of Clinical Psychiatry. 1999;60(12):857-860.

43. Kato T, Thie NM, Montplaisir JY, Lavigne GJ. Bruxism and orofacial movements during sleep. Dental Clinics of North America. 2001;45(4):657684.

Received: 31 October 2005; Accepted 14 February 2007; Published online: 30 July 2007. 